\title{
Erratum to: Combating residential segregation of ethnic minorities in European cities
}

\section{Gideon Bolt}

Erratum to: J Hous and the Built Environ (2009) 24 DOI 10.1007/s10901-009-9163-z

Under the heading 3 The papers in this issue, the names of Van Ham and Manly should read: Van Ham and Manley.

The online version of the original article can be found under doi:10.1007/s10901-009-9163-z.

G. Bolt $(\bowtie)$

Urban and Regional Research Centre Utrecht (URU), Universiteit Utrecht, Heidelberglaan 2, 3584 CS Utrecht, The Netherlands

e-mail: G.Bolt@geo.uu.nl 